\title{
INTERACTION ENERGY IN PAIRS OF PYRIDAZINIUM YLIDE-SOLVENT MOLECULES ESTIMATED BY SPECTRAL MEANS WITHIN THE CELL TERNARY SOLUTION MODEL
}

\author{
M. AVADANEI, ${ }^{1}$ D.O. DOROHOI ${ }^{2}$ \\ 1'P. Poni" Institute of Macromolecular Chemistry \\ (Iasi, Romania) \\ 2Faculty of Physics, "Al. I. Cuza" University \\ (Iasi, Romania)
}

PACS 78.30.Jw, 78.40.Dw

(C) 2012

Ternary solutions of three carbanion disubstituted pyridazinium ylides in a binary solvent containing two kinds of miscible simple liquids (active and inactive ones from the point of view of intermolecular interactions) are studied. Electronic absorption spectra are used to estimate the average statistical weights of the two solvents in the first solvation sphere of pyridazinium ylide molecules. This sphere contains a higher number of active solvent molecules than the rest of the solution. The relation established between the average statistical weights in the first solvation sphere and the molar concentrations of the two solvents in the solution allows us to evaluate the interaction energy in molecular pairs of the type pyridazinium ylide-active solvent and pyridazinium ylide-inactive solvent.

\section{Introduction}

Pyridazinium ylides [1, 2] are dipolar molecules important for their utilization as acid basic indicators [1, 3], as preliminary products in obtaining new heterocyclic compounds [4-6], or as components of some drugs with antifungal or antibacterial action [7-9]. Recently, they were tested in treating pulmonary diseases, infections with Koch's Bacillus, or with Escherichia Coli. As stable dipolar molecules, the carbanion disubstituted pyridazinium ylides can also be used in fundamental researches on the intermolecular interactions and the internal order in liquids, or in determining the interaction energy in molecular pairs.

Ternary solutions allow one to continuously modify the electro-optical parameters of a binary solvent by changing its molar concentration. Some cell models of ternary solutions were developed [10-14], and their applicability to different kinds of spectrally active molecules was analyzed. The average statistical weights of the first solvation sphere of the spectrally active molecules can be determined in these models. The interaction energy between two molecules (spectrally active molecule - solvent molecule) can be estimated in the limits of the ternary solution cell model, only by measuring the wavenumber in the maxima of the absorption or/and fluorescence electronic spectra.

\section{Main Results in the Ternary Solution Cell Model}

The ternary solutions are made of two miscible solvents in variable molar concentrations and a solute - spectrally active substance - in a very low concentration.

In the liquid cell model [14], the component molecules, considered as being rigid spheres, are placed into concentrical spheres having their centers at the center of a spectrally active molecule. Between the central molecule and its first solvation molecular shell, the very strong interactions take place [15-17]. The strength of intermolecular interactions decreases rapidly, as the distance to the center of the solvation sphere increases. Thus, in the cell model, the ternary solution is usually considered as being divided into macrocanonic systems consisting from a spectrally active molecule and its first solvation sphere. The number of macrocanonic systems is proportional to the molar concentration of the spectrally active substance in the ternary solution. The number of solvent molecules in the first solvation sphere is considered to be constant, but the thermal motion continuously changes the composition of the first solvation shell. In this process, the interaction energy between the spectrally active molecule and its solvation sphere can be modified by changes in the binary solvent composition. Conse- 
quently, when the total interaction energy between the central molecule and its first solvation shell is estimated, statistical methods must be applied in order to establish the average composition of a solvent in the first solvation sphere.

The statistical average weights $p_{1}$ and $p_{2}$ of the two solvents (index (1) for the active and index (2) for the inactive solvent from the point of view of intermolecular interactions) in the first solvation sphere of a spectrally active molecule are expressed as functions of the spectral shifts measured in the electronic absorption spectra as follows $[11,12]$ :

$p_{1}=\frac{\bar{N}_{1}}{N}=\frac{\nu_{t}-\nu_{2}}{\nu_{1}-\nu_{2}}$

and

$p_{2}=\frac{\bar{N}_{2}}{N}=\frac{\nu_{1}-\nu_{t}}{\nu_{1}-\nu_{2}}$.

Here, $\bar{N}_{1}$ and $\bar{N}_{2}$ are, respectively, the statistical average numbers of molecules of types (1) and (2) in the first solvation shell, in which only $N$ solvent molecules can exist (as the cell model of liquids predicts), and the wavenumbers in the maximum of the electronic absorption band are noted by $\nu_{1}$ for the binary solution achieved in the active solvent, $\nu_{2}$ for the binary solution achieved in the inactive non-polar solvent, and $\nu_{t}$ for the ternary solution, respectively.

The ratio of the average statistical weights is correlated with the ratio of the molar fractions $x_{1}$ and $x_{2}$ of the two solvents in the ternary solution [13] by the relation (3)

$\ln \frac{\nu_{t}-\nu_{2}}{\nu_{1}-\nu_{2}}=\ln \frac{x_{1}}{1-x_{1}}+\frac{w_{2}-w_{1}}{k T}$.

In relation (3), $k$ is the constant of ideal gases, $T$ is the Kelvin temperature of the ternary solution, and $w_{2}-w_{1}$ is the difference between the interaction energies in molecular pairs formed by the spectrally active substance with a solvent of types (2) and (1), respectively.

Relation (3) between the experimental data and the molar concentrations of the active solvent in a ternary solution certifies the applicability of the cell model to

T a b l e 1. Chemical structure of the studied pyridazinium ylides

\begin{tabular}{c|c|c|c|c}
\hline Nr. & Ylide & $-R$ & $-R_{1}$ & $-R_{2}$ \\
\hline 1 & $Y_{1}$ & $\mathrm{H}$ & $\mathrm{CO}-\mathrm{C}_{6} \mathrm{H}_{5}$ & $\mathrm{CO}-\mathrm{NH}-\mathrm{C}_{6} \mathrm{H}_{5}$ \\
2 & $Y_{2}$ & $\mathrm{H}$ & $\mathrm{CO}-\mathrm{C}_{6} \mathrm{H}_{5}-\mathrm{NO}_{2}(\mathrm{p})$ & $\mathrm{CO}-\mathrm{NH}-\mathrm{C}_{6} \mathrm{H}_{5}$ \\
3 & $Y_{3}$ & $\mathrm{H}$ & $\mathrm{CO}-\mathrm{C}_{6} \mathrm{H}_{5}-\mathrm{NO}_{2}(\mathrm{p})$ & $\mathrm{CO}-\mathrm{NH}-\mathrm{C}_{6} \mathrm{H}_{4}-\mathrm{Cl}(\mathrm{p})$ \\
\hline
\end{tabular}

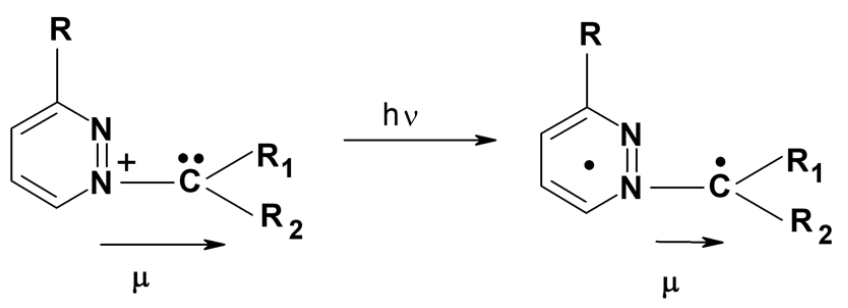

Fig. 1. Chemical structure of the studied pyridazinium ylides and the ICT mechanism

the spectral data. We intend to verify this relation for some derivatives of carbanion disubstituted pyridazinium ylides and to estimate the difference $w_{2}-w_{1}$ for some binary solvents.

\section{Experimental Part}

The studied carbanion disubstituted pyridazinium ylides were prepared by the methods described in $[1,2]$. The pyridazinium ylides obtained were checked by analytical (elemental) and spectral $\left({ }^{1} \mathrm{H}-\mathrm{NMR}\right.$ and IR) means from the point of view of purity. The structure of the studied pyridazinium ylides is illustrated in Fig. 1 and Table 1. The pyridazinium ylide concentrations in binary and ternary solutions were very low $\left(10^{-4}\right.$ $\left.10^{-3} \mathrm{~mol} / \mathrm{l}\right)$.

In Fig. 1, the intramolecular charge transfer (ICT) mechanism is also suggested. The ICT process, consisting of a transfer of the carbanion charge toward the heterocycle, is responsible for the appearance of the visible band of pyridazinium ylides.

The electronic spectra of binary and ternary solutions were recorded with a Specord UV VIS spectrophotometer with a data acquisition system.

Four solvents (see Table 1) (octanol (O), propionic acid (PA), 1,2-dichloroethane (1,2DCE), and chloroform (C)) were used for achieving binary and ternary solutions of pyridazinium ylides. The solvents were purchased from Merck Company and used without further purification.

The refractive index of the solvents was measured at room temperature at $\lambda=589.3 \mathrm{~nm}$ with an Abbe refractometer, and the electric permittivity with an Oehme DK-meter of RL type at $7 \mathrm{MHz}$.

The binary solvent was obtained by volumetric measurements, and then the molar fractions of each solvent were expressed by the known relations as functions of the density and the molar mass of the two liquids [18]. 


\section{Results and Discussions}

The global solvent action on a spectrally active molecule is usually named the universal (long-range) interaction [15].

In non-polar solutions, universal interactions of the dispersive type are predominant $[16,17]$, while, in solutions with polar components, the orientation and induction forces can have a decisive influence on the spectral shifts [15]. The dispersive interactions are due to the spontaneous molecular dipole moments, and their supply is usually expressed by functions of the solvent refractive index. In dipolar solutions, a dipolar molecule can be oriented in the electric field created by the neighboring molecules at the point, where it is placed, and a supplemental dipole moment can be induced by the local reactive electric field [17] acting at each point of the solution. The orientation-induction interactions determine the spectral shifts, which can be expressed as functions of the electric permittivity $\varepsilon$ and the refractive index $n[14,15]$. The universal interactions between the spectrally active molecules (as pyridazinium ylides) and the solvent molecules determine the value of solvation energy, when specific interactions are absent.

In some solutions, specific (short-range or quasichemical) interactions of the hydrogen bond type or of that of proton or electron transfer can act between some parts of molecules [18-20].

The long-range forces are radial and act on the spectrally active molecules in all directions; they affect the distribution of the valence electron cloud and can be evidenced especially in electronic spectra. The short-range interactions act locally, only between molecular parts; they affect especially the vibration and rotation spectra.

In solvent theories [15-17], only universal forces are taken into consideration, while the specific interactions are neglected.

Pyridazinium ylides are dipolar molecules in their ground state. As dipolar molecules, pyridazinium ylides can participate both in the induction-orientation universal interactions and in the specific interactions in protic solvents, in which their carbanion can be a part of the

T a b l e 2. Refractive index, electric permittivity, and wavenumbers at the ICT maximum of the studied ylides in the chosen solvents

\begin{tabular}{c|c|c|c|c|c}
\hline Ylide & $n$ & $\varepsilon$ & $Y_{1}$ & $Y_{2}$ & $Y_{3}$ \\
\hline PA & 1.394 & 3.34 & 21396 & 22410 & 21660 \\
O & 1.4215 & 9.8 & 21720 & 22120 & 21540 \\
1,2 DCE & 1.539 & 4.5 & 21760 & 20610 & 20790 \\
C & 1.446 & 4.7 & 20466 & 20320 & 20630 \\
\hline
\end{tabular}

hydrogen bond with the hydroxyl proton. The dipolar moment of pyridazinium ylides diminishes by excitation $[3,14]$. So, the solvation energy in their ground state is bigger than that corresponding to their excited state [1820]. The ICT absorption bands of pyridazinium ylides shift to the blue side (See Table 2), when they pass from a non-polar to a polar solvent or from an aprotic to a protic solvent.

Each pair of solvents chosen for this study (see Table 2) contains one aprotic and one protic solvent able to make specific interactions by hydrogen bonds with the ylide carbanion. The wavenumbers measured at the ICT band maximum of carbanion disubstituted pyridazinium ylides in each solvent are given in Table 2 .

The molar concentration of the protic solvent and the wavenumbers in the ICT visible electronic band in ternary solutions $\mathrm{PA}+\mathrm{C}+$ ylide and $\mathrm{O}+1,2 \mathrm{DCE}$ + ylide are given in Table 3. In Fig. 2, the graphical representations of the average statistical weights as a function of the molar fraction of the protic solvent are presented. In the plane $\left(x_{1}, p_{1}\right)$, the points of all graphs from Fig. 2 are placed above the first bisector, showing that the inequality $x_{1}<p_{1}$ is valid for all representations in Fig. 2. Only the initial and final points in these representations are on the first bisector $\left(x_{1}=p_{1}\right)$. Consequently, it follows from Fig. 1 that the first solvation sphere of all three pyridazinium ylides is enriched in protic solvent molecules, compared to the rest of the ternary solution. The average statistical weight of the protic solvent in the first solvation sphere of the pyridazinium ylides under study is also higher than the octanol molar concentration in the binary solvent.

The dependences $p_{1}$ vs. $x_{1}$ for the ternary solutions of carbanion disubstituted pyridazinium ylides $Y_{1}$ and $Y_{2}$ evidence the higher contribution of the orientation induction interactions and of the specific interactions to

T a b l e 3. Molar fraction of the protic solvent and the wavenumbers at the maximum of the ICT visible band in ternary solutions of pyridazinium ylides

\begin{tabular}{c|ccc|c|c|c|c}
\hline \multirow{2}{*}{$\chi_{1}$} & \multicolumn{2}{|c|}{$(\mathrm{PA}+\mathrm{C}) \nu\left(\mathrm{cm}^{-1}\right)$} & \multirow{2}{*}{$\chi_{1}$} & \multicolumn{3}{c}{$(\mathrm{O}+1.2 \mathrm{DCE}) \nu$} & $\left(\mathrm{cm}^{-1}\right)$ \\
\cline { 2 - 3 } \cline { 7 - 8 } & $Y_{1}$ & $Y_{2}$ & $Y_{3}$ & & $Y_{1}$ & $Y_{2}$ & $Y_{3}$ \\
\hline 0 & 20466 & 20320 & 20630 & 0 & 20760 & 20610 & 20790 \\
0.053 & 20710 & 20820 & 21120 & 0.025 & 21000 & 21100 & 20910 \\
0.109 & 20870 & 21110 & 21300 & 0.052 & 21250 & 21350 & 21030 \\
0.263 & 21180 & 21760 & 21480 & 0.141 & 21510 & 21770 & 21300 \\
0.517 & 21360 & 22140 & 21570 & 0.330 & 21680 & 22020 & 21490 \\
0.763 & 21380 & 22330 & 21590 & 0.597 & 21700 & 22080 & 21520 \\
1.000 & 21396 & 22410 & 21660 & 1.000 & 21720 & 22120 & 21540 \\
\hline
\end{tabular}



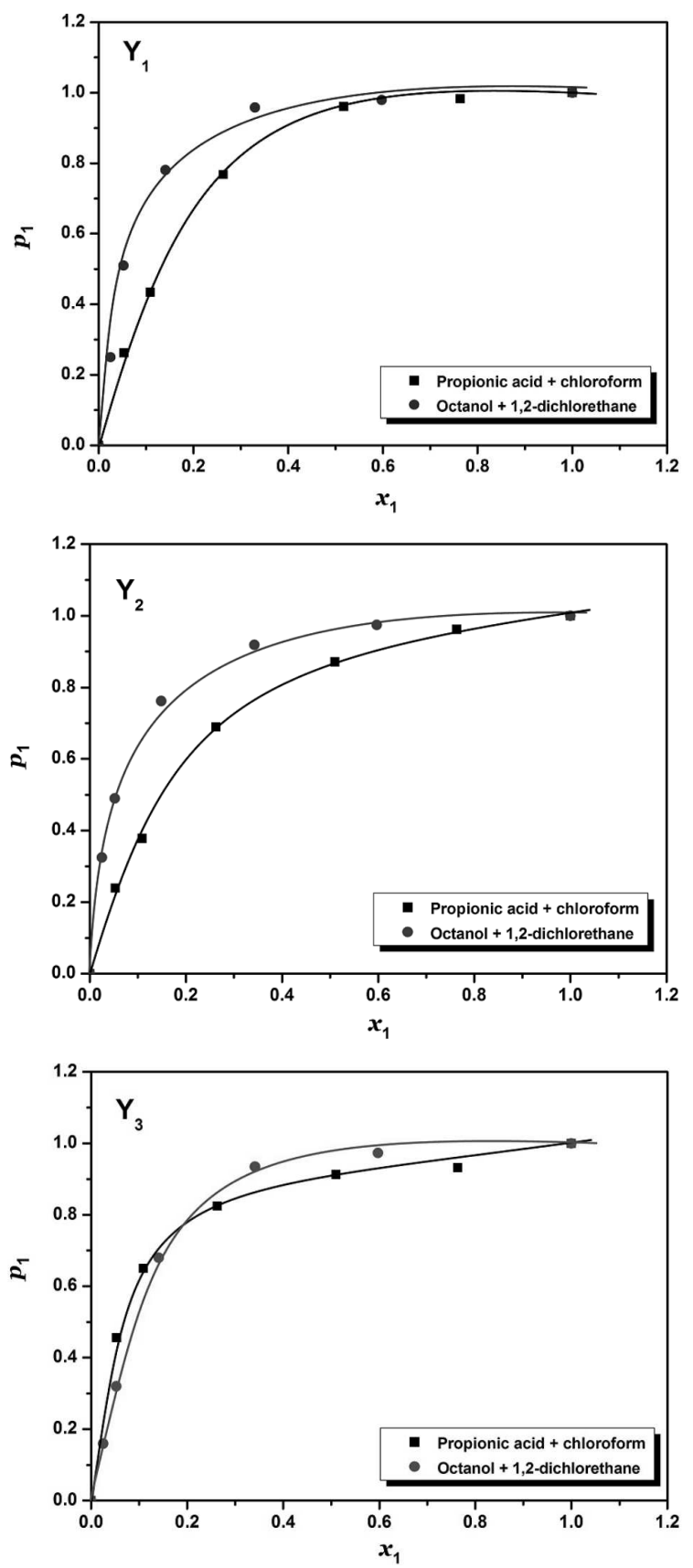

Fig. 2. $p_{1}$ vs. $x_{1}$ for the first solvation sphere of $Y_{1}, Y_{2}$, and $Y_{3}$ ylides

the solvation energy of the ylide ground electronic state compared to its excited electronic state.

In Fig. 3, we give the dependences of $\ln \frac{p_{1}}{1-p_{1}}$ as a function of $\ln \frac{x_{1}}{1-x_{1}}$. The slopes and the intercepts of the lines of type (3) are given in Tables 4 and 5 for ternary solutions $\mathrm{PA}+\mathrm{C}+$ ylide and $\mathrm{O}+1,2 \mathrm{DCE}+$ ylide. The slopes of line (3) are close to 1 , proving the appli-
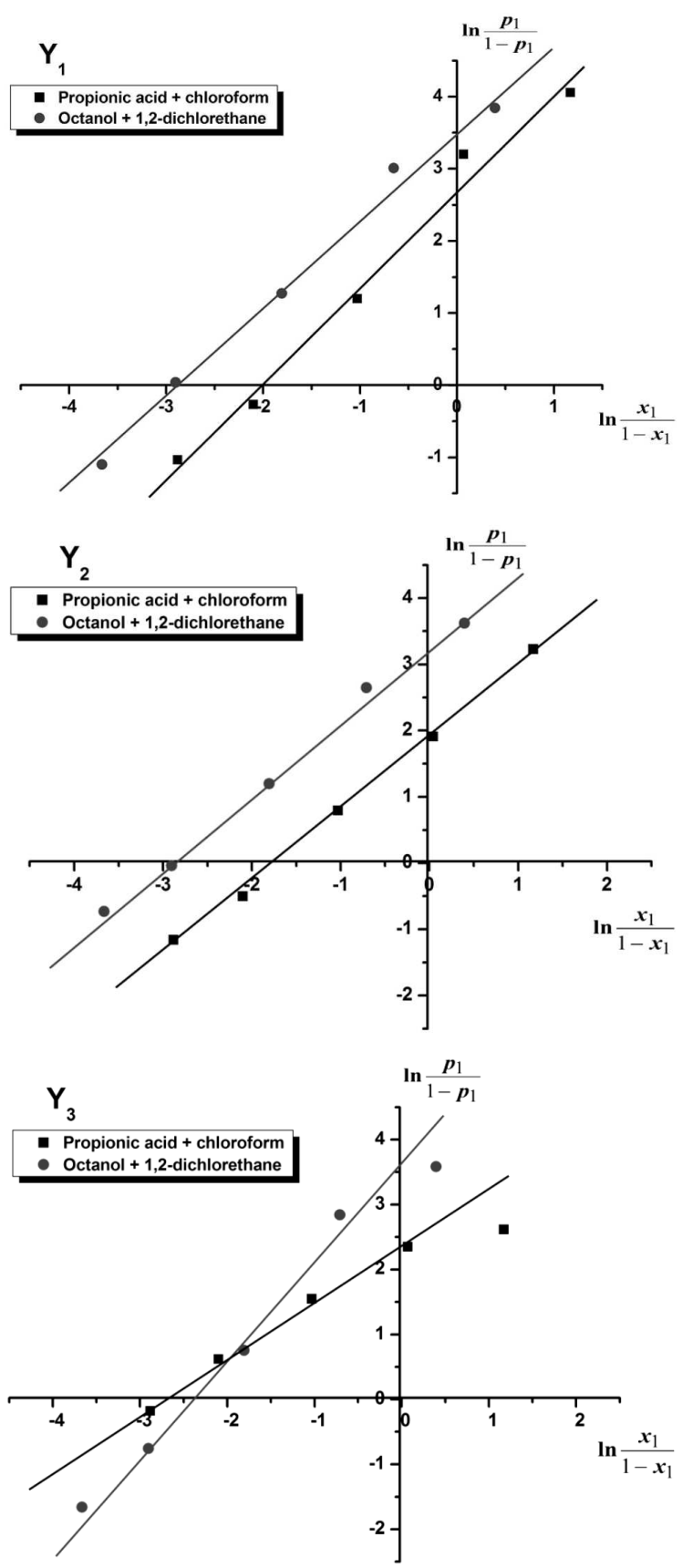

Fig. 3. $\ln \frac{p_{1}}{1-p_{1}}$ vs. $\ln \frac{x_{1}}{1-x_{1}}$ for $Y_{1}, Y_{2}$, and $Y_{3}$ ylides

cability of the ternary solution cell model to the studied compounds. In the last columns of Tables 4 and 5 , the difference $w_{2}-w_{1}$, expressed in Joule, is given. The values obtained are in accordance with the literature data [18].

Propionic acid and chloroform have appropriate values of refractive indices and dielectric constants. This results 
T a b l e 4. Slopes $(m)$, cuts at origin $(n)$, their estimation errors $\Delta(m)$ and $(\Delta n)$; correlation coefficient $R$ of linear dependences (3), and $w_{2}-w_{1}$ for ternary solution $\mathbf{P A}+\mathbf{C}+$ ylide

\begin{tabular}{c|c|c|c|c|c|c}
\hline Ylide & $m$ & $\Delta m$ & $n$ & $\Delta n$ & $R$ & $k T(n \pm \Delta n),\left(10^{-21} \mathrm{~J}\right)$ \\
\hline$Y_{1}$ & 1.3318 & 0.0916 & 2.7036 & 0.1595 & 0.0993 & $10.9368 \pm 0.645$ \\
$Y_{2}$ & 1.0943 & 0.0270 & 1.9077 & 0.0471 & 0.999 & $7.7175 \pm 0.1905$ \\
$Y_{3}$ & 0.8533 & 0.0423 & 2.3542 & 0.0785 & 0.997 & $9.5234 \pm 0.3175$ \\
\hline
\end{tabular}

in that the contributions of universal interactions with pyridazinium ylide molecules in these solvents are comparable. Consequently, one can suppose that the contribution of universal interactions to the pair energy pyridazinium ylide-propionic acid and pyridazinium ylidechloroform is the same, and the difference $w_{2}-w_{1}$ contains only the contribution of the specific interactions. Due to the fact that the contribution of the specific interactions in chloroform can be approximated by zero, one can consider that the difference $w_{2}-w_{1}$ approximates the hydrogen bond energy in the ground state of the molecular pair pyridazinium ylide-propionic acid.

When the linear dependence (3) is compared with a line equation

$y=m x+n$,

one can establish the correspondence

$n=\frac{w_{2}-w_{1}}{k T}$.

When the cell model of ternary solutions is applicable, the difference $w_{2}-w_{1}$ can be estimated in the limits of this model. One of the conditions for the model applicability is a unitary slope of the lines in the plane determined by the values of $\ln \frac{p_{1}}{1-p_{1}}$ and $\ln \frac{x_{1}}{1-x_{1}}$.

In the pair $\mathrm{O}+1,2 \mathrm{DCE}$, the two solvents have different parameters $n$ and $\varepsilon$ (see Table 2). Thus, in their binary solutions with pyridazinium ylides, the universal interactions have different contributions which cannot be neglected in the $w_{2}-w_{1}$ difference. Consequently, by comparing the data from Tables 4 and 5 , we obtain that the values of $w_{2}-w_{1}$ are greater in the binary solvent $\mathrm{O}+1,2 \mathrm{DCE}$ as compared with binary solvent PA $+\mathrm{C}$, in which the difference between the universal interactions tends to zero, due to the appropriate values of the electro-optical parameters of the two component liquids.

If one considers $N_{A}=6.06310^{23} \mathrm{~mol}^{-1}$, one can appreciate the hydrogen bond energy for a mole of ylide. The values estimated for the difference $w_{2}-w_{1}$ by the method used in this study are in accordance with the values from the literature.
T a b l e 5. Slopes $(m)$, cuts at origin $(n)$, their estimation errors $\Delta(m)$ and $(\Delta n)$, correlation coefficient $R$ of linear dependences (3), and $w_{2}-w_{1}$ for ternary solution $\mathrm{O}+1,2 \mathrm{DCE}+$ ylide

\begin{tabular}{c|c|c|c|c|c|c}
\hline Ylide & $m$ & $\Delta m$ & $n$ & $\Delta n$ & $R$ & $k T(n \pm \Delta n),\left(10^{-21} \mathrm{~J}\right)$ \\
\hline$Y_{1}$ & 1.2545 & 0.0892 & 3.6164 & 0.2027 & 0.992 & $14 \pm 0.8199$ \\
$Y_{2}$ & 1.1074 & 0.0397 & 3.2641 & 0.0902 & 0.998 & $13.2042 \pm 0.3648$ \\
$Y_{3}$ & 1.5166 & 0.1118 & 3.7397 & 0.2829 & 0.994 & $15.1282 \pm 1.1444$ \\
\hline
\end{tabular}

\section{Conclusions}

The cell model of ternary solutions can be applied to the studied pyridazinium ylides with disubstituted carbanion. The results obtained in this study prove the ternary solution inhomogeneity, showing a higher concentration of the polar and protic solvents near the pyridazinium ylide molecules compared to the rest of the solution. The difference between the interaction energies in the molecular pairs pyridazinium ylide-protic solvent and pyridazinium ylide-aprotic solvent is estimated on the basis of the cell model of ternary solution. For two solvents, in which the universal interactions have a comparable contribution, the difference $w_{2}-w_{1}$ approximates the energy of specific interactions of the hydrogen bond type between ylide carbanion and $-\mathrm{OH}$ groups of the protic solvent.

1. I. Zugravescu and M. Petrovanu, N-ylide Chemistry (McGraw-Hill, London, 1976).

2. M.V. Tri, PhD Thesis, Researches for obtaining new pyridazinium ylides ("Alexandru Ioan Cuza" Univ., Faculty of Chemistry, 1976).

3. D.O. Dorohoi, D.H. Partenie, L.M. Chiran, and C. Anton, J. Chim. Phys. Phys.-Chim. Biol. 91, 419 (1994).

4. Y. Kazarzi and G. Surpateanu, Heterocycles 51, 863 (1999).

5. M. Petrovanu and I. Zugravescu, Cycloaddition Reactions (Acad. Press, Bucharest, 1987).

6. A. Pawda, 1,3-Dipolar Cycloaddition Chemistry (Wiley Interscience, New York, 1984).

7. M. Ungureanu, I. Mangalagiu, G. Grosu, and M. Petrovanu, Ann. Pharm. Fr. 55 (2), 69 (1997).

8. I. Olariu, M. Caprosu, G. Grosu, M. Ungureanu, and M. Petrovanu, Roum. Biotech. Lett. 4, 365 (1999).

9. I. Mangalagiu, G. Mangalagiu, M. Roman, M. Caprosu, and Petrovanu, M., Ann. Pharm. Fr. 58, 86 (2000). 
10. Y.T. Mazurenko, Opt. Spektr. XXXIII, 1060 (1972).

11. V. Pop, D.O. Dorohoi, and M. Delibas, An. Stiin. Univ. Al. I. Cuza, Iasi, XXXII, s. Ib, 79 (1986).

12. D.O. Dorohoi and V. Pop, An. Stiint. Univ. "Al. I. Cuza", Iasi, XXXIII, s. Ib, 78 (1987).

13. D.O. Dorohoi, M. Avadanei, and M. Postolache, Opt. Adv. Mat. Rapid Comm. 2, 511 (2008).

14. D.O. Dorohoi, J. Mol. Struct. 704, 31 (2004).

15. N.G. Bakhshiev, Spectroscopy of Intermolecular Interactions (Nauka, Leningrad, 1972) (in Russian).

16. C. Reichardt, Solvent Effects in Organic Chemistry, (Wiley-VCH, Weinheim, 2004).

17. E.G. McRae, J. Phys. Chem. 61, 562 (1957).

18. M. Avadanei, D.O. Dorohoi, and N. Puica-Melniciuc, Proc. of SPIE, International Conference on Applications of Optics and Photonics, 8001, 80012D-8 (2011).

19. D.O. Dorohoi and V. Holban, J. Mol. Struct. 293, 133 (1993)
20. C. Gheorghies, L.V. Gheorghies, and D.O. Dorohoi, J. Mol. Struct. 887, 122 (2008).

Received 28.09.11

ЕНЕРГІЯ ВЗАЕМОЗВ'ЯЗКУ ПАР МОЛЕКУЛ РОЗЧИННИКА ТА ІЛІДУ ПІРИДАЗИНУ, ОЦНЕНА СПЕКТРАЛЬНИМИ МЕТОДАМИ У КЛІТИННІЙ МОДЕЛІ ТЕРНАРНОГО РОЗЧИНУ

М. Авадані, Д.О. Дорогой

Р ез ю м е

Вивчено тернальні розчини трьох ілідів піридазину з двозаміщеним карбаніоном у бінарному розчиннику, що має два види змішуючих простих рідин (активну і пасивну з точки зору міжмолекулярної взаємодії). На основі спектрів поглинання електронів оцінено середні статистичні ваги обох розчинників у першій сольватній сфері ілідів піридазину, де концентрація активних молекул розчинника більша, ніж в оточуючому середовищі. Оцінено енергію взаємодії у парах молекул ілід піридазину-активний розчинник та ілід піридазинунеактивний розчинник. 